Klaudy Kinga 1992. Empirical Research in Translation Studies. Lecture held at the $8^{\text {th }}$ International Congress on Translation and Interpreting. Charles University, Praha Czech Republic, 20-22 October, 1992. In: Hrala, M. (ed.) 1998. Translatologica Pragensia VI. Praha: Univerzita Karlova. 19-25.

\title{
Empirical Research in Translation Studies
}

\author{
Kinga Klaudy
}

\section{Personal theorizing vs. experimental research}

Hans Vermeer in his plenary lecture held at the Vienna Congress of Translation Studies ${ }^{1}$ raised the following question: is there any progress in thinking about translation or are we only reinterpreting old ideas over and over again?

Unfortunately, the long tradition of personal, impressionistic and anecdotal reflections on translation still virulent. Old terms like "faithfulness", "the spirit of the original" were replaced by seemingly more sophisticated terms like "equivalence of the TL reader's response", but if the SL and TL reader's response can not be tested, the appeal to "equivalence of response" - as Juliane House pointed out - "is really of no more value than the philologists' criterion of "capturing the spirit of the original" (House 1977).

In her book "A Model for Translation Quality Assessment" (first published in 1977) Juliane House gave a short overview of suggestions for experimental studies and experiments that have actually been undertaken in the field of translation research. This overview is a very short one indeed, and could not be longer at that time. It consists mainly of suggestions of Nida and Taber and not of experiments actually undertaken.

During the following ten years nevertheless empirical research has taken off the ground and experimental methods were introduced at various institutions. In his article "Experimenta-

\footnotetext{
1 "Translation Strategies and Effects in Cross-Cultural Value Transfer and Shifts"
} 
tion in Translation Studies" published in 1991, Gideon Toury pointed out that "the introduction of empirical methods proved to be a true landmark in the evaluation of the discipline..." (45). The overview of experiments actually undertaken listed in Gideon Toury's article is already much longer than House's overview given ten years earlier.

\section{Product oriented vs. process oriented research}

Toury made distinction between "product oriented" and "process oriented" translation research, and gave account of product oriented experiments like cloze test and the questionnaire method, used by Mary Snell-Hornby, Tiina Puurtinen and Sonja Tirkkonen Condit and also "process oriented" experiments like the collection of introspective data known as "thinking aloud protocols" carried out by Hans Krings, Wolfgang Lörschner and others.

\section{Product oriented experiments in Hungary}

I have to confess, that in 1978 I carried out this experiment totally unaware of any similar research of others, and only years later when I happened to be in Finland at the TRANSIF seminar on "Empirical Research in Intercultural Studies and Translation", had I realized that I am not alone, and there are several colleagues mainly in Finland and Israel working in a similar direction.

\section{The concept of quasi-correctness}

In this lecture I would like to speak about a series of "product oriented" experiments carried out in Hungary first in 1978 and than repeated several times over the following years.

The purpose of my research was to describe the so called "quasi-correctness" (QC) of translated texts made by professional translators, and our trainees, postgraduate students of the Translation Department at the University of Budapest. The term "quasi-correctness" was introduced by the Hungarian scholar, Ferenc Papp in connection with second language acquisition, but later it turned out to be a very useful term in translation studies as well. It refers to slight differences between translated TL texts and authentic TL texts, that can not be detected on the sentence level (assuming that all sentences in translated texts are grammatically correct target language sentences) but became conspicuous only on the text level, yet may seriously 
hamper the readability and consequently the comprehensibility of translation.

\section{Text-level differences between THT and AHT}

The view, that there is a text-level difference between translated Hungarian (THT) and authentic Hungarian texts (AHT) was only a hypothesis based on my intuitive impression. The view, that this kind of difference will influence negatively the readability of translated texts was also a hypothesis based on no more, than intuition. The first hypothesis was to be verified by the method of textual comparison of translated Hungarian texts and authentic Hungarian texts. The second hypothesis was to be verified by testing the readers reactions on translated Hungarian texts.

As in this paper I would like to deal only with the second, experimental part of my research, a will not go into details about the principles and methods of textual comparison of translated TL texts with authentic TL texts ( a very detailed analysis of all these problems can be found in Inkeri Vehmas Lehto's book, published in 1989). But it seems to be necessary to speak about the results of the textual comparison because of my second hypothesis, that is, the syntactic and textual properties of translated texts may cause difficulties in the readability of these texts.

\section{Syntactic differences between THT and AHT}

On the basis of textual comparison it seemed to be justified to state that under the indirect influence of any Indoeuropean source language there will occur well detectable differences in the syntactic properties and topic-comment structure of the translated Hungarian text in comparison with an authentic Hungarian text. The syntactic differences are mainly frequency differences: some elements will be under- or over-represented in translations. Translated texts will contain more non finite clauses and fewer finite clauses than authentic ones. The nominal phrases in translated texts will become longer and will contain longer strings of left-branching premodifiers than in authentic texts. It should be noted that finnish researchers (Inkeri Vehmas Lehto 1989, Tiina Puurtiinen 1992) comparing Indoeuropean languages with Finnish, which is similarly to Hungarian a Finno-Ugric language, came to very similar conclusions. 


\section{Topic-comment differences between THT and AHT}

The differences in topic-comment structure can only partly be measured statistically: for example the topic part of the sentences will be longer and less explicit in translated texts than in authentic texts, translated texts will contain fewer connective elements etc. Part of these differences can not be measured statistically: for example the fuzziness of some part of the sentence because of the lack of clear borderline markers between topic and comment.

\section{Acceptability of QC texts}

The conclusion, that these differences will cause difficulty in comprehension could have been drown without any experiment - one may say. But interestingly enough, it is not so self evident even among the practitioners of the field. There is a rather generally accepted view, that in the case of non-literary (academic or scientific) texts where the content has priority over the form, syntactic properties are not so relevant, and specialists of the field would easily understand the clumsy and unnatural translations as well.

This view can be rejected both theoretically or experimentally. Theoretically, we may say of course that in the case of non-literary texts, when the reader wants to extract first of all the cognitive information from the text, all extra efforts on decoding the syntactic information may negatively influence understanding. We may also claim, that if the communication channel of the reader is overloaded by the use of unfamiliar and infrequent forms, the process of extracting information from the text will inevitably slow down.

Furthermore, we may use metaphors like this: the scientific text has to be similar to a clear window. The quasi-correct translations are similar to a dirty window: you are able to see through the window, distinguish the contours of things behind the window but not without difficulty, not without making extra efforts.

\section{Testing readers' reactions to $\mathrm{QC}$ translations}

In preparing my experiments to test readers' reactions I wanted to know, in what extent the readers of quasi-correct translations can realize that the window is dirty.

Putting aside the metaphors and returning to the Toury's classification of experiments, my first experiment would fall into the category of "product oriented" experiments using ques- 
tionnaires. The purpose of the experiment was to test how the readers identify and evaluate quasi-correct translations.

The persons, taking part in the experiment had to be, of course, everyday consumers of scientific texts. There were 130 persons involved into the experiment: language teachers and linguists (40), university students, majoring in foreign languages (46), university students, majoring in other subjects than languages (44).

The participants were given five Hungarian scientific texts selected from the field of different social sciences, partly translated, partly authentic, and were given a questionnaire to each of the texts containing following questions:

(1) Is this text a translation or an authentic Hungarian text?

(2) Why do you think that it is a translation ( or an authentic Hungarian text)?

(3) If it is a translation, how do you evaluate it?

The texts did not contain proper names, geographic names, names of institutions, or other culturally bound lexemes, referring to the non-Hungarian origin of the author. All the five texts had extremely abstract subject matter, they were discussing different problems of sociology, science of science and aesthetics. In order to avoid the reading problems caused by the content and not by the form of the text, I tried to find texts of similar complexity, however hopeless this task is because of the necessarily different academic background of the participants.

Having got the texts, they were asked to read them carefully, neither too slowly and neither too quickly, in their usual, normal reading tempo, as they do it in their everyday routine when they want to extract information from the text. They were allotted 30 minutes to work. I did not want to give them too much time to work, because in real life they have to read quickly (normally two minutes for one page should have been enough), but this relatively long time was necessary because of the second two questions, which required reasoning rather than decision.

\subsection{Identification of QC translations}

First, I will speak very briefly about the identification part of the experiment. As I have 
mentioned, the participants had to answer the question, whether the text, they read, was a translated text or an authentic Hungarian text. With five texts all in all, each of the 130 participants had to made 5 decisions. This meant 650 decisions. The number of correct decisions was in total 372 (57,23\%), The average of the good decisions inside the different groups was the following: 3.35 correct decision (out of five) per person among the language teachers and linguists, 3.15 correct decisions per person among the students majoring in languages, and 2.56 correct decision per person among the students majoring not in languages.

These results are not surprising at all. To identify a text as translation or original requires a certain degree of general textual awareness or sensitivity, which is certainly higher among the language teachers and linguists and would be language teachers than among the students majoring in sciences. We may say, that all in all, the differences between the translated texts and authentic texts were recognized by the majority of participants. On the basis of the identification part of the experiment we certainly could not say anything about the degree of intuitiveness of decisions, that is why we asked them for a justification of their decisions in the second part of the experiment.

\subsection{The justification of the decisions}

In this short presentation I certainly can not give a detailed description of all kind of justifications given by the participants of the experiment. As these justifications may reveal a lot about the reader's expectations concerning the translated text I would like to cite a couple of extremely contradictory remarks concerning both the translations and the originals.

(1) (a) "It must be a translation because there are a lot of foreign words in it."

(b) "It is an original Hungarian text because there are a lot of foreign words in it. If it were a translation, foreign words would have been translated by the translator."

(2) (a) "It is a translation because there are a lot of too complicated sentences in it."

(b) "It is an original Hungarian text because there are a lot of complicated sentences in

it. If it were a translation, the too complicated sentences would have been split by the 
translator."

(3) (a) "It is a translation because it has many long left- branching nominal structures, which are rarely used in Hungarian"

(b) "It is an original Hungarian text because it has long left-branching nominal structures, and left-branching is characteristic only of Finno-Ugric languages."

(4) (a) "It is a translation because there are a lot of clumsy and unnatural sentences in it."

(b) "It is an original Hungarian text because there are a lot of clumsy and unnatural sentences in it. If it were a translation these sentences would have been better formulated by the translator."

Providing proof for the general uncertainty of readers' expectations concerning translations and originals, was not an aim of my research. It is only an unexpected and interesting by-product.

\section{References}

House, J. (1977) A Model for Translation Quality Assessment. Tübingen: Narr.

Krings, H. (1986) Was in den Köpfen von Übersetzern vorgeht. Tübingen: Narr.

Lörschner, W. (1992) Translation Performance, Translation Process and Translation Strategies. Tübingen: Narr.

Papp, F. (1984) The Russian of Hungarian people whose Russian is first rate. In: Papp Ferenc (ed.) Contrastive Studies Hungarian-Russian. 139-155. Budapest: Akadémiai Kiadó.

Puurtinen, T. (1989) Assessing acceptability in translated children's books. Target. 1:2. 201-213.

Puurtinen, T. (1992) Towards a Definition of Acceptability in Translation. A Comparison of Two Finnish Translation of The Wizards of Oz. Licenciate Thesis. University of Savonlinna. 
Snell-Hornby, M. (1983) Metaphorical though and translation: Taking a stand on P. Newmark. Trier: L.A.U.T. (Serie A.Paper No.108.)

Tirkkonen-Condit, S. (1989) Professional vs. non-professional translation. A think-aloud protocol study. In: Seguinot, C. (ed.) The translation process. ed. by Toronto: H.G. Publications.

Toury, G. (1991) Experimentation in Translation Studies: Achievements, Prospects and Some Pitfalls. In: Tirkkonen-Condit,S. (ed.) Empirical Research in Translation and Intercultural Studies. 45-67. Tübingen: Narr.

Vehmas-Lehto, I. (1989) Quasi-Correctness. A critical study of Finnish translations of Russian Journalistic texts. Helsinki: Neuvostoliitto Instituutti. 